\title{
Bridging a Complete Transection Lesion of Adult Rat Spinal Cord with Growth Factor-Treated Nitrocellulose Implants
}

\author{
John D. Houle and Mei Kheng Ziegler \\ Department of Anatomy, University of Arkansas for Medical Sciences, Little Rock, AR 72205, USA
}

\begin{abstract}
SUMMARY
The ability of a substrate bound neurotrophic factor to promote growth of ascending sensory axons across a complete transection lesion of the rat spinal cord was examined in a transplantation model. Aspiration lesions created a $3 \mathrm{~mm}$ long cavity in the upper lumbar spinal cord of adult rats. Five weeks after injury two strips of nerve growth factortreated nitrocellulose were implanted, each in a medio-lateral position, and apposed to the rostral and caudal surfaces of the cavity. Control animals received untreated nitrocellulose implants. Fetal spinal cord tissue was transplanted alongside and between these strips. Six weeks post transplantation, animals were sacrificed and vibratome sections through the grafts were processed for immunocytochemical demonstration of ingrowing axons expressing calcitonin gene-related peptide (CGRP-IR). Immunolabeled axons were abundant at the caudal interface between host tissue and the NGF-treated nitrocellulose implants, with dense fascicles of fibers abutting the grafts. As the distance from the caudal surface increased some CGRP-IR fibers extended into the fetal tissue although most appeared to remain oriented in a longitudinal course adjacent to the nitrocellulose. Labeled axons were evident along the entire length of the nitrocellulose and appeared to aggregate at the rostral tip of the implant, with many fibers extending into the host spinal cord rostral to the lesion/transplant site. When untreated nitrocellulose was implanted, fewer
\end{abstract}

\footnotetext{
Reprint address:

John D. Houle

Department of Anatomy

University of Arkansas for Medical Sciences

Little Rock, AR 72205, USA
}

labeled axons appeared to extend beyond the caudal host-graft interface. Most CGRP-IR axons displayed limited association or contact with the untreated nitrocellulose in this condition. Computer-assisted quantitative analysis indicated that NGF-treated nitrocellulose supported regrowing host axons for nearly three times the length exhibited by axons associated with non-treated nitrocellulose implants. These results indicate that substrate bound nerve growth factor has the capacity to enhance the regrowth of ascending sensory axons across a traumatic spinal cord injury site. The potential to reestablish functional contacts across such a lesion may be heightened by the ability of neurotrophic factors to promote more extensive axonal regrowth.

\section{KEY WORDS}

neurotransplantation, spinal cord injury, CNS regeneration, NGF

\section{INTRODUCTION}

The potential for axonal regrowth following a traumatic injury to the spinal cord has been demonstrated in several different lesiontransplantation models. Previous investigations indicated that injured neurons are capable of regrowing their axonal processes if an appropriate environment, such as fetal central nervous system tissue or a segment of peripheral nerve, is provided as a substratum for elongation $/ 1,4,11,24 /$. Under these experimental conditions, both axons descending from the brain $/ 17 /$ and ascending sensory axons $/ 12 /$ will cross a host-graft interface and, particularly in the case of a neonatal host $/ 2,3 /$, extend for a considerable distance within a fetal 
spinal cord tissue transplant. The type of injury does not appear to influence the ability or the extent of regrowth, as considerable integration of host and graft tissues has been demonstrated following contusive injuries, small dorsal column lesions as well as after a complete transection lesion $15,6,23,26 /$. The potential for axonal regeneration appears to be retained by certain neurons for a much longer time than was previously realized. There is evidence that many neurons associated with a chronic spinal cord injury have the capacity for regeneration for at least two months after injury $/ 14,16 /$

While there is ample evidence that the response to CNS injury does not necessarily lead to an abortive regenerative effort, it must be realized that under some conditions the extent of regeneration is somewhat limited $/ 18 /$. In an adult rat, growth of host axons into a fetal CNS tissue graft generally proceeds for only a few $\mathrm{mm}$ before growth is stopped. Generally, there is no apparent directionality to the ingrowth, i.e. axons seem to wander through the transplant, unlike those that extend into a peripheral nerve graft where the path for axonal extension is well established. That sparse ingrowth may be attributed to the presence of inhibitory molecules associated with certain nonneuronal cells $/ 29,30 /$, the formation of an impenetrable glial scar associated with the injury site $/ 25 /$ or to limitations in the growth response of neurons $/ 7 /$ demonstrates the complexity of the systems involved.

Attempts have been made to influence the direction of growing axons and to promote more extensive axonal regrowth within the spinal cord. Relatively sparse axonal growth occurred along an untreated strip of nitrocellulose apposed to the developing rat corticospinal tract; however, when laminin was added to the nitrocellulose axonal elongation was supported for a considerable distance $/ 28 /$. Whether the regeneration of axons in an adult could be influenced to a similar extent was addressed in a study in which substrate bound nerve growth factor (NGF) was implanted into the injured spinal cord $/ 13 /$. Results from this study demonstrated that regeneration of sensory axons from injured dorsal roots could be enhanced in terms of the number of axons and distance of regrowth. There was also evidence that the NGF- treated substratum provided directional guidance for the regrowth of axons towards specific areas of the spinal cord. An earlier report from this laboratory described the possibility of regrowth from ascending sensory axons into fetal spinal cord tissue transplanted into a chronic spinal cord lesion cavity $/ 12 /$. Together, these results formed the basis of the present study in which implanted NGFtreated nitrocellulose strips spanned a complete transection lesion site of the adult rat spinal cord to determine whether the regeneration of ascending sensory axons across such an extensive lesion could be promoted to a similar extent.

\section{MATERIALS AND METHODS}

Adult female Sprague-Dawley rats were anesthetized with ketamine $(80 \mathrm{mg} / \mathrm{kg})$ and xylazine $(10 \mathrm{mg} / \mathrm{kg})$ and a laminectomy performed over the upper lumbar spinal cord. A complete transection lesion was created by aspiration to form a cavity 3 $\mathrm{mm}$ in length. After hemostasis was achieved the cavity was covered with a dacron reinforced silastic film and the meningeal membranes closed with 10-0 silk sutures.

Five weeks after injury the lesion site was exposed and the cavity expanded by approximately $0.5 \mathrm{~mm}$ in both a rostral and caudal extent as encapsulating glial scar tissue was removed. Rectangular strips of nitrocellulose paper $(0.2 \mu \mathrm{m}$ pore size, approximately $2 \times 4 \mathrm{~mm}$ ) were implanted vertically into the cavity such that the ends were gently apposed to the rostral and caudal surfaces of the lesion cavity. Two strips were placed into each cavity, one apposed to the medio-lateral portion of each side of the spinal cord. The nitrocellulose had been treated either with nerve growth factor (NGF, Collaborative Research Inc.) by immersion in a 10 $\mu \mathrm{g} / \mathrm{ml}$ solution for 12 hours at $37^{\circ} \mathrm{C}$ in a humidified chamber or immersed in Hanks' balanced salt solution which was used to dilute the NGF Animals receiving this untreated nitrocellulose implant $(n=4)$ were considered to be part of the control group. Eight animals received the NGF-treated implants. Fetal spinal cord (FSC) tissue (day 14 of gestation) was dissected free of surrounding meningeal membranes and cut to fit the length of the lesion cavity. Segments of this tissue were placed along 
the lateral side of each nitrocellulose strip and a third FSC segment transplanted between the two strips. Silastic film was placed over the transplants and the musculature closed in layers. Postoperatively, animals received Buprenex $(0.1 \mathrm{mg} / \mathrm{kg})$ as an analgesic and Penicillin Procaine G $(10,000 \mathrm{U})$ as an antibiotic.

Six weeks after transplantation, animals were perfused transcardially with $4 \%$ paraformaldehyde, $0.1 \%$ glutaraldehyde in $0.1 \mathrm{M}$ phosphate buffer. Tissue blocks containing the transplant were removed and sectioned in a horizontal plane with a vibratome. Sections were processed for calcitonin gene-related peptide immunoreactivity (CGRP-IR, Peninsula Labs.) by the PAP method using DAB as the chromogen and stained with thionin after mounting on glass slides.

A Biographics (Dallas, TX) image analysis system was used to measure the length of axonal growth along treated or untreated strips of nitrocellulose. Sections exhibiting the maximal extent of growth for each animal were used. The ratio of axonal growth to the length of the nitrocellulose strip was determined, as was the mean distance of axonal extension.

\section{RESULTS}

In most cases the nitrocellulose strips maintained their vertical position during the growth and maturation of the FSC tissue transplants. The FSC tissue grew to fill the cavity, apposing the host spinal cord both rostrally and caudally, occasionally with some intervening tissue growth between the nitrocellulose and the host. Cystic cavitation was rare and occurred more frequently at the rostral graft-host interface. In all animals (treated and untreated nitrocellulose) there was obvious extension of CGRP-IR axons from the host spinal cord caudal to the transplant, across the graft-host interface and into the fetal tissue transplant. The presence of transplant tissue between the host and nitrocellulose implant did not appear to adversely influence access of ingrowing axons to the nitrocellulose, but served as a common substratum for the initial stages of axonal regrowth in all animals (with either treated or untreated nitrocellulose implants). The outgrowth of immuno- labeled axons differed greatly between animals receiving the NGF-treated nitrocellulose implants compared to the untreated implants, as dense bundles of fibers extended towards the treated nitrocellulose, whereas fewer, more widely scattered axons were observed crossing into the fetal tissue associated with the untreated nitrocellulose.

\section{Untreated nitrocellulose implants}

At the interface between the transplants and the host spinal cord caudal to the transplant, CGRP-IR axons were found to extend within the fetal tissue for less than $2 \mathrm{~mm}$ from the interface. Some of these axons appeared close to the nitrocellulose implant (Figure 1), but the majority of fibers were dispersed within the fetal tissue. There was no obvious direction to the course of growth taken by these regrowing axons and there did not seem to be any strong association with the untreated nitrocellulose strips. From the mid portion of the nitrocellulose to the rostral end there were few CGRP-IR axons within the fetal tissue. Within the host spinal cord rostral to the transplant there were scattered CGRP-IR axons that approached the implants, but most appeared to terminate at the host-graft interface.

The mean distance for axonal growth associated with untreated implants was $1.2 \mathrm{~mm}$. This represented an association with approximately $30 \%$ of the available length of nitrocellulose, with the range being from 10 to $55 \%$.

\section{NGF-treated nitrocellulose implants}

The extent of axonal growth across the caudal graft-host interface and along the entire length of the nitrocellulose implants treated with NGF was much greater than what was observed with the untreated implants. Dense aggregates of CGRP-IR axons, particularly where the ascending dorsal column fibers apposed the transplant, were present within the fetal tissue and in close association with the nitrocellulose (Figures 2 and 3). The extension of these fibers along the nitrocellulose gave the appearance of an orderly path for growth. While not all axons came close to the treated nitrocellulose 


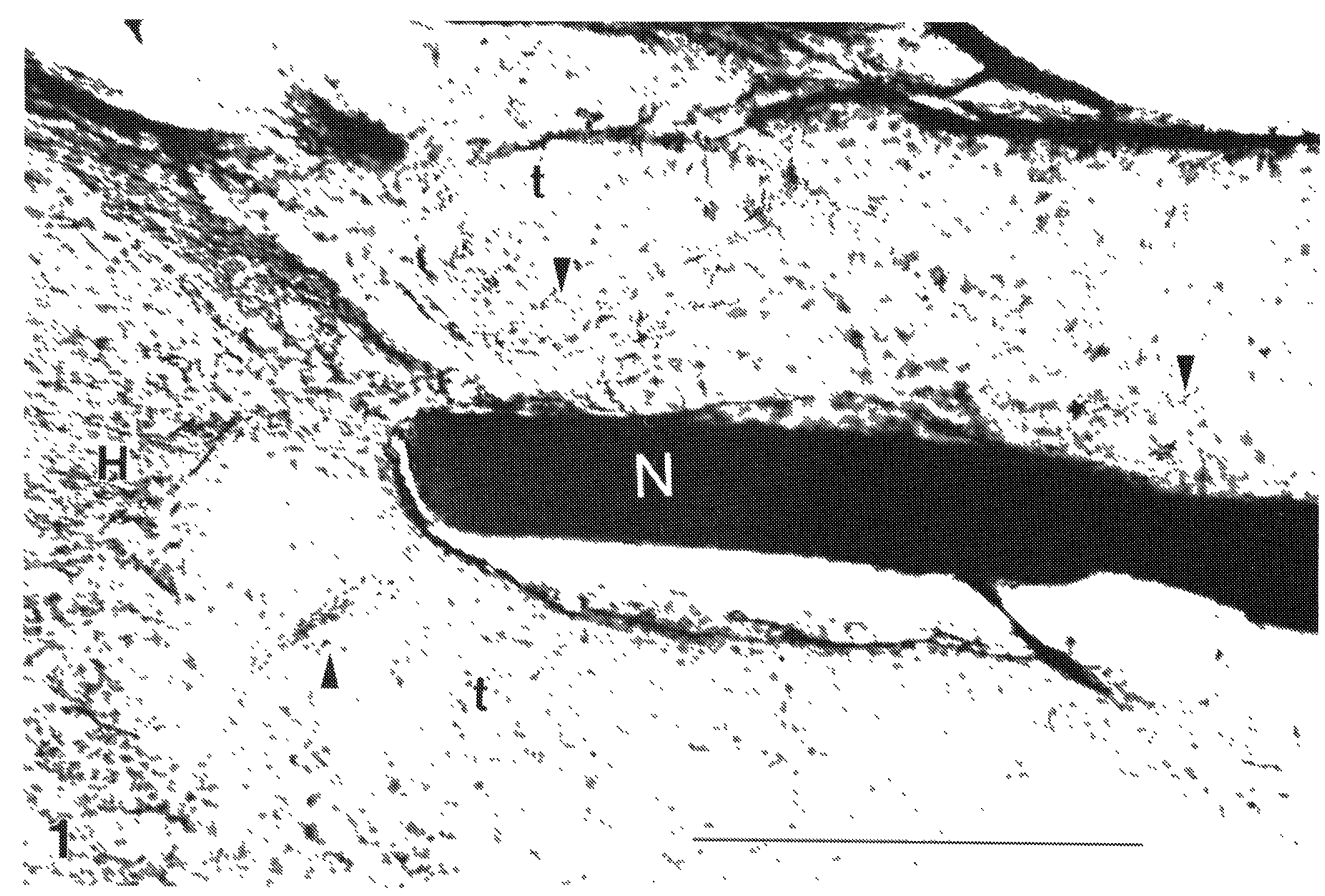

Fig. 1: Untreated nitrocellulose implant. Few CGRP-IR axons (arrowheads) have extended from the host spinal cord (H) caudal to the lesion into the fetal spinal cord tissue transplant ( $t$ ). Most fibers appear scattered within the transplant, with little association with the nitrocellulose implant $(\mathrm{N})$. Horizontal section. Bar $=0.5 \mathrm{~mm}$.

implant, greater extension was evident in those that did approximate the implant.

There was some decrease in the density of fiber bundles associated with the nitrocellulose as the distance from the caudal graft-host increased (Figure 4), with most axons remaining relatively close to the nitrocellulose. The layer of nonneuronal cells immediately adjacent to the nitrocellulose provided an area which appeared to be particularly supportive of the elongation of these fibers (Figure 4). There also appeared to be enhanced growth within the fetal tissue between nitrocellulose implants that became closely apposed to each other. Within this area, non-neuronal cells appeared to be more numerous than in other regions of the fetal tissue transplant, although it is not clear that this had an effect on the extent of axonal growth. The physical narrowing of the fetal tissue due to close apposition of the nitrocellulose implants may have contributed to the apparent funneling of axons through this region, although this was not evident with the untreated nitrocellulose implants.
Numerous CGRP-IR axons surrounded the rostral ends of the NGF-treated nitrocellulose implants, with some evidence that axons extended beyond the implant, across the rostral graft-host interface and into the host spinal cord (Figures 5 and 6). Even in cases where there was growth of fetal transplant tissue between the nitrocellulose and rostral host spinal cord, some axons extended through this region to reach the host tissue. In sections displaying CGRP-IR axons apposed to the host spinal cord, there was no evidence that these axons were derived from descending host axons close to the lesion/transplant site, as few immunolabeled axons appeared in the host tissue just rostral to the apparent termination of the axons traveling through the transplant.

Quantitative measurements indicated that a mean of $85 \%$ of the length of the NGF-treated implant appeared to support growth of host axons. The range was from 65 to $100 \%$, with the average length being $3.4 \mathrm{~mm}$ or nearly three times that observed with untreated nitrocellulose implants. 

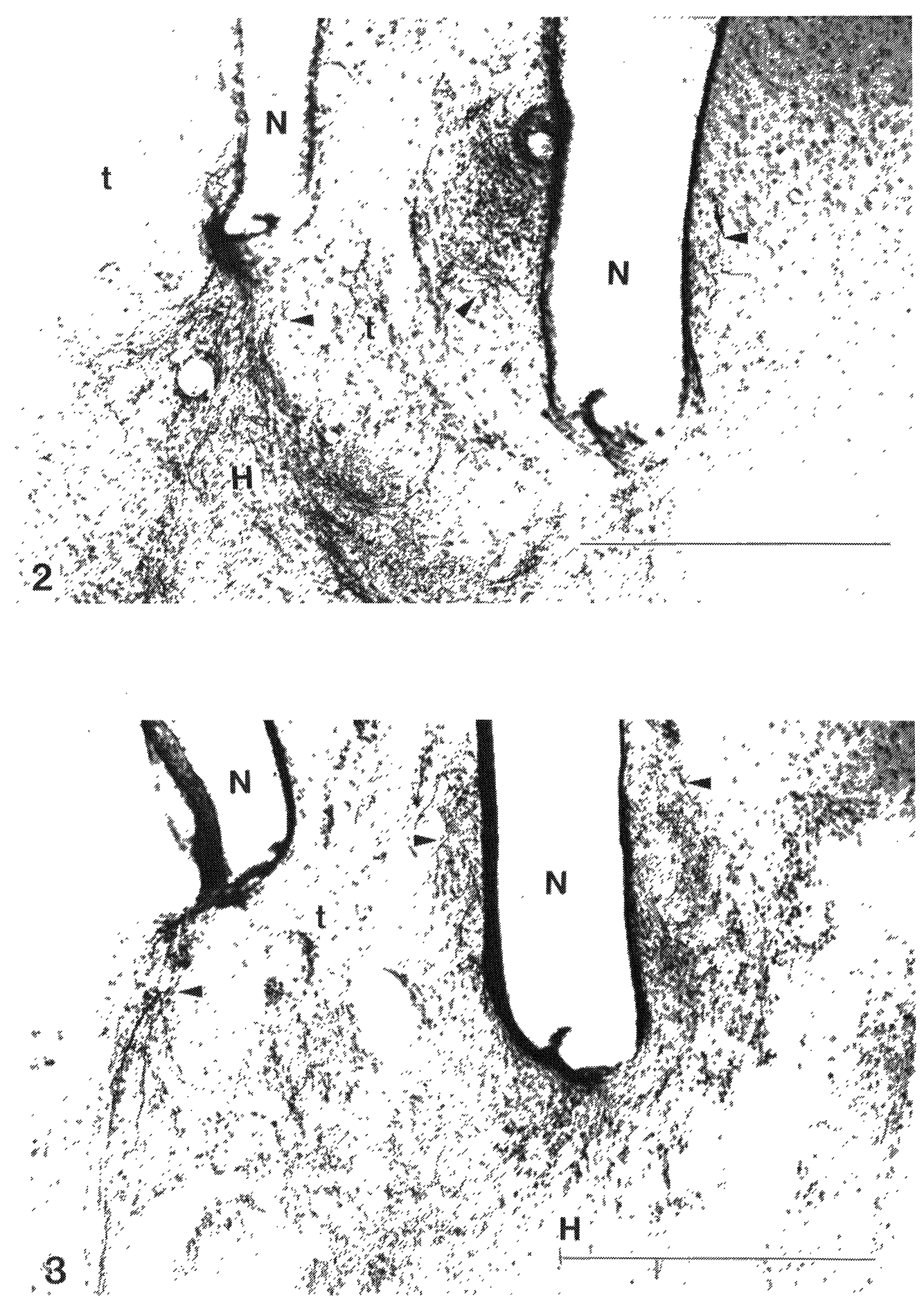

Figs. 2 and 3: NGF-treated nitrocellulose implant. Caudal to the lesion, CGRP-IR axons (arrowheads) extend across the host (H) - graft ( $\mathrm{t}$ ) interface and appear in close proximity to the nitrocellulose implant $(\mathrm{N})$. In these serial sections, bundles of axons are found along all sides of the nitrocellulose. Compare the density of fibers here with the sparse fiber ingrowth with untreated nitrocellulose implants as shown in Figure 1. Horizontal section. Bar $=0.5 \mathrm{~mm}$. 


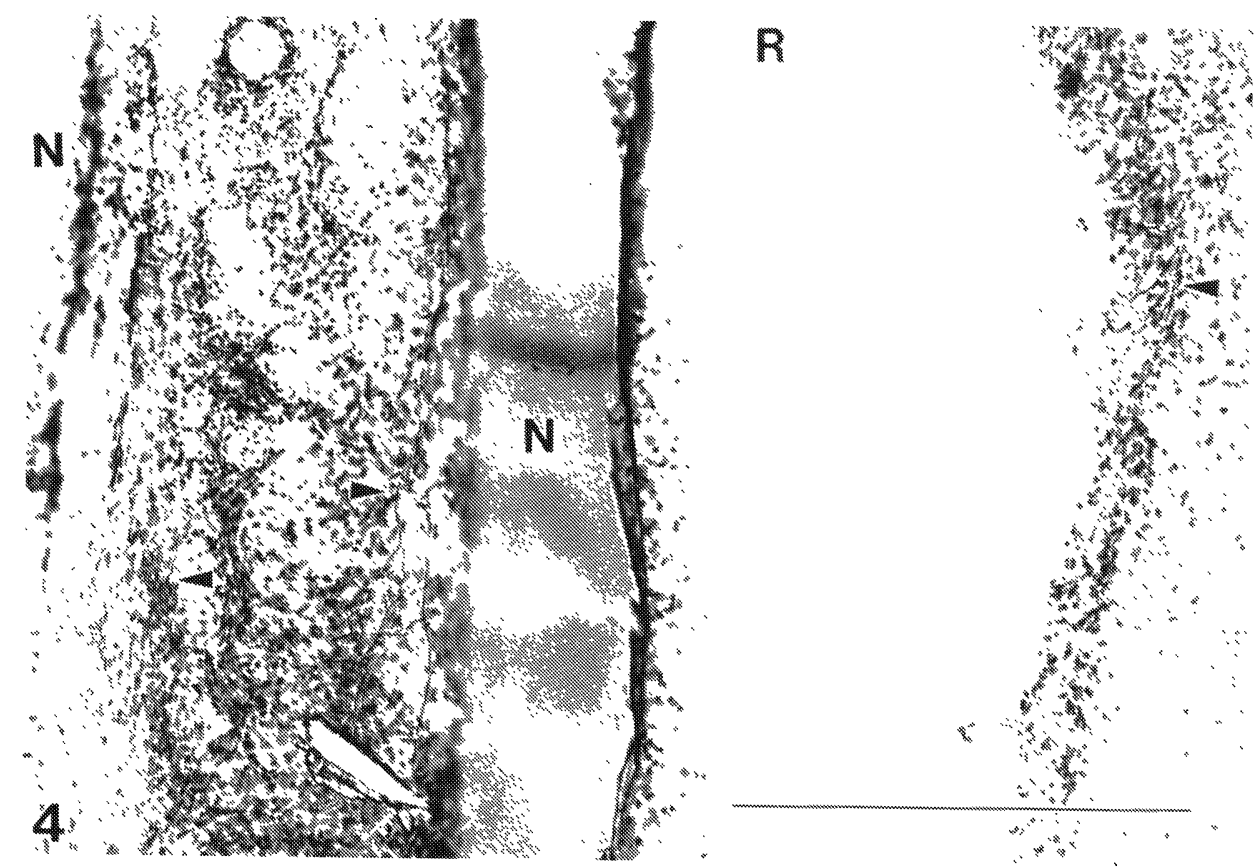

Fig. 4: NGF-treated nitrocellulose implant. Midway along a $4 \mathrm{~mm}$ long nitrocellulose implant (N), CGRP-IR axons (arrowheads) remain oriented in a caudal to rostral $(\mathrm{R})$ plane, associated with transplant tissue lining the nitrocellulose. Abundant labeled fibers appear within the fetal transplant tissue between the nitrocellulose strips rather than lateral to the implants. Horizontal section. Bar $=0.5 \mathrm{~mm}$.

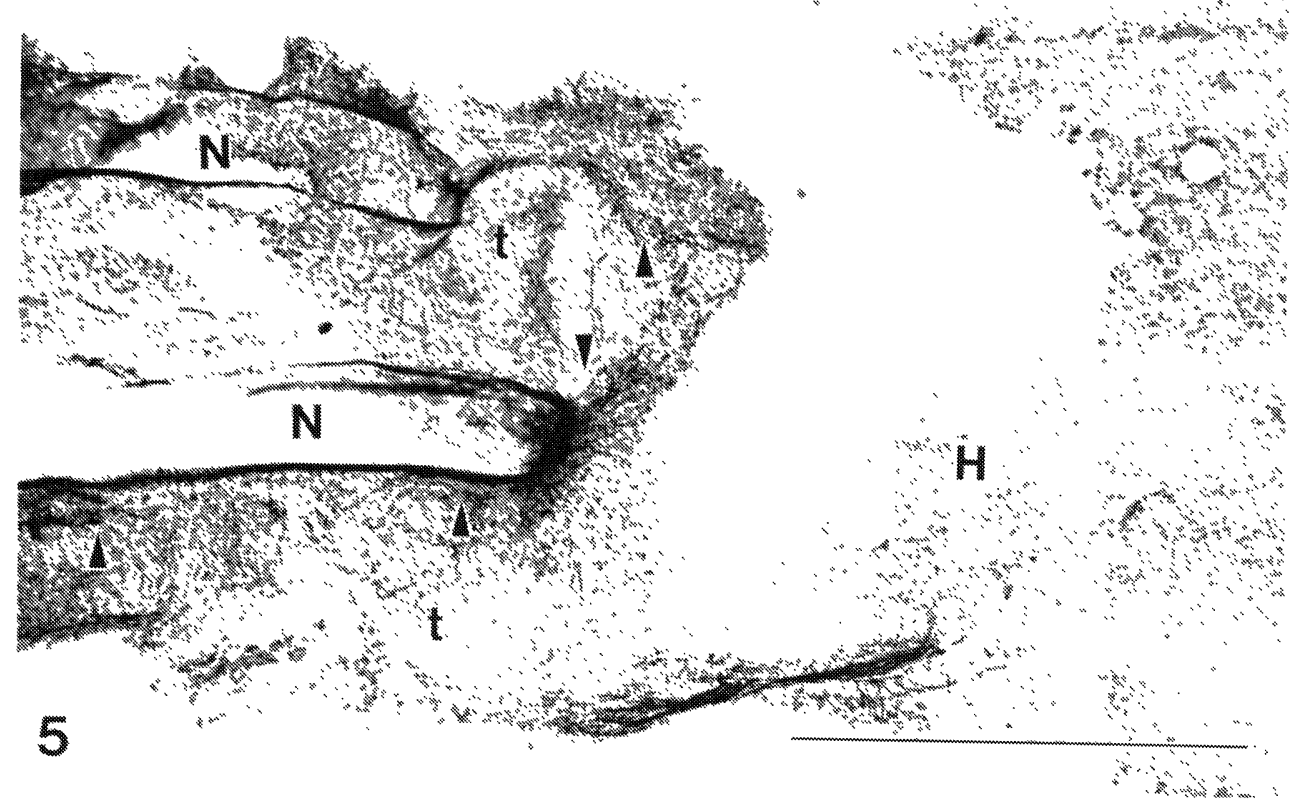

Fig. 5: NGF-treated nitrocellulose implant. At this rostral graft $(t)$ - host $(H)$ interface, numerous CGRP-IR axons (arrowheads) are found along the nitrocellulose $(\mathrm{N})$, with further extension rostrally towards the host spinal cord. A portion of the tissue at the interface was disrupted during processing of the tissue. The bundle of fibers at the bottom of the figure likely represent descending fibers from dorsal roots entering the spinal cord rostral to the lesion. Horizontal section. Bar $=1 \mathrm{~mm}$. 


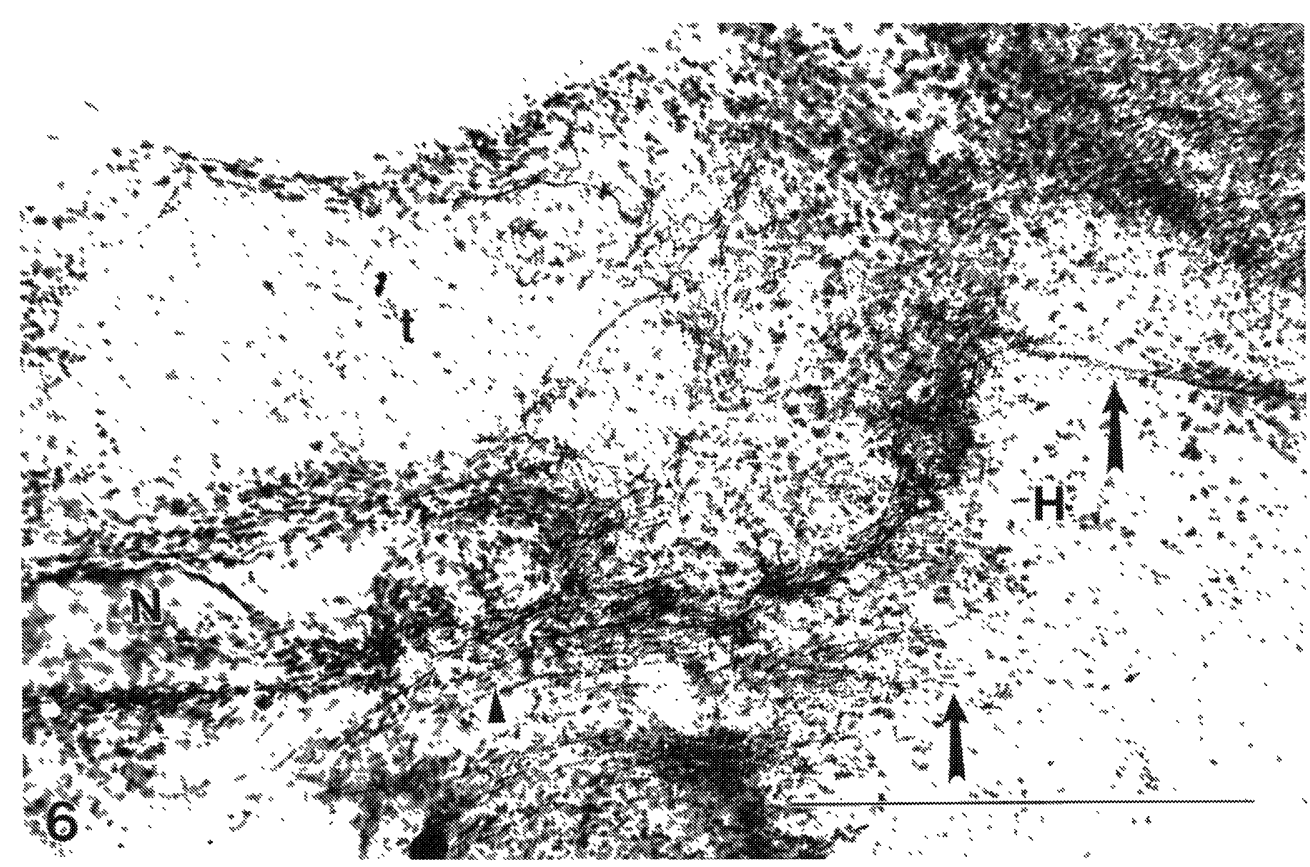

Fig. 6: NGF-treated nitrocellulose implant. Many CGRP-IR axons (arrowheads) are found at this rostral interface of transpiant (t) and host $(\mathrm{H})$ tissue, with a few fibers (arrows) crossing into the host spinal cord. Only a partial section through one of the nitrocellulose implants $(\mathrm{N})$ is evident in this field. Horizontal section. Bar $=0.5 \mathrm{~mm}$.

\section{DISCUSSION}

This study provides an indication of the regenerative potential of the chronically injured spinal cord and the ability of a substrate bound neurotrophic factor to promote the regrowth of axons across an extensive lesion. Ascending sensory axons expressing a specific neuropeptide, calcitonin gene-related peptide (CGRP), readily cross the interface between the spinal cord caudal to a chronic lesion cavity and a fetal spinal cord tissue transplant. When a nitrocellulose strip treated with NGF is apposed to the host spinal cord regrowing axons often extended along the entire length of the nitrocellulose implant (nearly $4 \mathrm{~mm}$ ) with many fibers appearing to extend into the host spinal cord rostral to the lesion site. This remarkable growth was in contrast to the paucity of fibers associated with a nitrocellulose implant that had not been treated with NGF, with few axons extending beyond the caudal portion of the fetal tissue transplant. This result also provides further evidence that neuronal components associated with the injured spinal cord maintain the capacity for axonal growth for prolonged periods after the initial injury, as the substratum (FSC tissue) for regrowth was not available until five weeks after the initial spinal cord injury.

The presence of substrate bound NGF may have several roles in influencing the regrowth of CGRPIR axons. 1) Axonal growth beyond the caudal portion of the FSC tissue transplant was more abundant (i.e. larger fascicles of fibers) in the presence of NGF-treated nitrocellulose. 2) Axonal growth appeared to be directed along the nitrocellulose implant towards the rostral pole of the implant, and 3) the distance of fiber growth was elevated above that observed with untreated nitrocellulose implants (mean of $3.4 \mathrm{~mm}$ vs. 1.2 $\mathrm{mm}$ ). All of these parameters suggest a multifaceted action of NGF in promoting the regrowth of ascending sensory axons across a spinal cord lesion site.

That bound NGF has a significant role in promoting the regrowth of these ascending sensory axons is clearly demonstrated by the present results 
when compared to the extent of growth observed with fetal tissue transplants alone /12/. In that case, numerous CGRP-IR axons grew into the fetal spinal cord tissue, but there was little orientation to their growth as fibers were scattered randomly throughout the caudal regions of the transplant. Furthermore, few axons extended more than $1 \mathrm{~mm}$ beyond the host-graft interface, in contrast to the present results where there was abundant, directed axonal growth for up to $4 \mathrm{~mm}$. The possibility of promoting axonal growth across a complete transection lesion represents a significant improvement to our previous transplantation approaches and suggests a potential for reestablishment of anatomical continuity between separated regions of the spinal cord.

The importance of having NGF present, particularly when provided bound to a solid substratum, is further illustrated by the studies of Hagg et al. /10/ in which acellular peripheral nerve grafts were placed between the septum and hippocampal formation. Few cholinergic axons appeared within untreated grafts, whereas treatment with NGF prior to grafting encouraged significant axonal ingrowth. A similar finding was achieved by the administration of NGF to the distal end of a peripheral nerve graft placed into the spinal cord 17/. Under such conditions the presence of NGF was especially influential on the regrowth of axons from small sized neurons of the dorsal root ganglia, the majority of which are known to express CGRP. We have demonstrated in an earlier study that the intraspinal regeneration of CGRP-IR axons from a severed dorsal root can be enhanced by NGFtreated nitrocellulose implants /13/. Thus, while we have chosen to examine a very select group of axons within the injured spinal cord, they belong to neurons that likely represent some of the most sensitive neurons to the neurotrophic action of NGF that are associated with the adult spinal cord $/ 21 /$.

Whether NGF exerts a direct or indirect effect upon axonal regrowth has been widely disputed. While several tissue culture studies indicate a direct action on the extension of axons $/ 9 /$, more recent studies suggest that NGF may interact with nonneuronal cells associated with either the nitrocellulose graft or a peripheral nerve graft to facilitate or mediate a directed growth response
$/ 10,13,15,27 /$. Electron microscopic examination of cells lining the nitrocellulose implant indicates that an orderly array of non-neuronal cells appears when NGF is bound to the implant, while an unorganized mesh of cells appears with untreated nitrocellulose implants $/ 15 /$. Importantly, macrophages are abundant along the nitrocellulose in the presence of NGF, but are relatively sparse along an untreated implant. Interestingly, regions of spinal cord demonstrating a mild injury response to trauma, where many macrophages would be expected, signals an area where regeneration of sensory axons would be most likely to occur 131 . Current observations of extensive axonal growth between parallel strips of NGF-treated nitrocellulose, an area where the non-neuronal cell content appears to be greater than in other regions of the FSC tissue transplant, are in agreement with these previous findings. Furthermore, the lack of direct contact between regrowing axons and NGF-treated nitrocellulose supports the idea that NGF may mediate a non-neuronal cell response that plays an important role in the initial stages of axonal growth.

Various substances have been applied to nitrocellulose in an attempt to influence axonal growth. Results from these studies, as in others, generally center around the debate of whether a substance provides a permissive substratum for elongation or whether there is an instructive influence as well $/ 20 /$. Some substances, such as laminin, have been found to be principally permissive molecules, in that growing axons adhere quite readily to a surface coated with laminin $/ 19,22 /$, but there does not appear to be much guidance or directionality of growth provided by laminin. One exception is the case of oriented growth of the developing corticospinal tract as demonstrated by Schreyer and Jones /28/. Our experience with laminin-treated nitrocellulose implants supports the notion that it is not a highly effective molecule for guidance of regenerating axons after dorsal root injury $/ 13 /$. It seems clear that the presence of an NGF-treated substratum provides more than a permissive environment for axonal elongation, particularly as many axons extended along the entire length of the treated nitrocellulose implant without straying off into the transplanted fetal spinal cord tissue. 


\section{ACKNOWLEDGEMENTS}

This work was supported by a grant from the National Institutes of Health, NINDS, \# NS-26380.

\section{REFERENCES}

1. Aguayo AJ. Axonal regeneration from injured neurons in the adult mammalian central nervous system. In: Cotman CW, ed, Synaptic Plasticity. New York: Guilford Press, 1985; 457-484.

2. Bregman B. Spinal cord transplants permit the growth of serotonergic axons across the site of neonatal spinal cord transection. Dev Brain Res 1989; 34: 265-279.

3. Bregman BS, Bernstein-Goral $\mathrm{H}$. Both regenerating and late-developing pathways contribute to transplantinduced anatomical plasticity after spinal cord lesions at birth. Exp Neurol 1991; 112: 49-63.

4. Das GD. Neural transplantation in mammalian brain: some conceptual and technical considerations. In: Wallace RB, Das GD, eds, Neural Tissue Transplantation Research. New York: SpringerVerlag, 1983; 1-64.

5. Das GD. Neural transplantation in the spinal cord of the adult mammal. In: Kao CC, Bunge R, Reier PJ, eds, Spinal Cord Reconstruction. New York: Raven Press, 1983; 367-396.

6. Das GD. Neural transplantation in spinal cord under different conditions of lesions and their functional significance. In: Das GD, Wallace, RB, eds, Neural Transplantation and Regeneration. New York: Springer-Verlag, 1986; 1-61.

7. Fernandez F, Pallini R, Mercanti D. Effects of topically administered nerve growth factor on axonal regeneration in peripheral nerve autografts implanted in the spinal cord of rats. Neurosurgery $1990 ; 25: 37-$ 42.

8. Fawcett JW. Intrinsic neuronal determinants of regeneration. TINS 1992; 15: 5-8.

9. Gundersen RW, Barrett JN. Characterization of the turning response of dorsal root neurites toward nerve growth factor. J Cell Biol 1980; 87: 546-554.

10. Hagg T, Gulati AK, Behzadian MA, Vahlsing HL, Varon S, Manthorpe M. Nerve growth factor promotes CNS cholinergic axonal regeneration into acellular peripheral nerve grafts. Exp Neurol 1991; 112: 79-88.

11. Horvat JC. Transplants of fetal neural tissue and autologous peripheral nerves in an attempt to repair spinal cord injuries in the adult rat. Paraplegia 1991; 29: 299-308.

12. Houle JD, Reier PJ. Regrowth of calcitonin generelated peptide (CGRP) immunoreactive axons from the chronically injured rat spinal cord into fetal spinal cord tissue transplants. Neurosci Lett 1989; 103: 253258.
13. Houle JD, Johnson JE. Nerve growth factor (NGF)treated nitrocellulose enhances and directs the regeneration of adult rat dorsal root axons through intraspinal neural tissue transplants. Neurosci Lett 1989; 103: 17-23.

14. Houle JD. Demonstration of the potential for chronically injured neurons to regenerate axons into intraspinal peripheral nerve grafts. Exp Neurol 1991; 113: 1-9.

15. Houle JD. Regeneration of dorsal root axons is related to specific non-neuronal cells lining NGF-treated intraspinal nitrocellulose implants. Exp Neurol 1992; 118: 133-142.

16. Houle JD, Wright JW, Ziegler MK. After spinal cord injury, chronically injured neurons retain the potential for axonal regeneration. In: Marwah J, Teitelbaum $\mathrm{H}$, Prasad K, eds, Neural Transplantation, CNS Neuronal Injury and Regeneration. Boca Raton: CRC Press, $1994 ; 103-118$

17. Jakeman LB, Reier PJ. Axonal projections between fetal spinal cord transplants and the adult rat spinal cord: A neuroanatomical tracing study of local interactions. J Comp Neurol 1991; 307: 311-334.

18. Kromer LF, Cornbrooks CJ. Identification of trophic factors and transplanted cellular environments that promote CNS axonal regeneration. In: Azmitia EC, Björklund A, eds, Cell and Tissue Transplantation into the Adult Brain. Ann NY Acad Sci 1987; 495: 207 225.

19. Lander $A D$, Fujii DK, Reichardt LF. Laminin is associated with the neurite outgrowth-promoting factors found in conditioned media. Proc Natl Acad Sci USA $1985 ; 82$ : 2183-2187.

20. Lemmon V, Burden SM, Payne HR, Elmslie GJ, Hlavin ML. Neurite growth on different substrates: permissive versus instructive influences and the role of adhesive strength. J Neurosci 1992; 12: 818-826.

21. Lindsay RM. Harmar AJ. Nerve growth factor regulates expression of neuropeptide genes in adult sensory neurons. Nature (London) 1989; 337: 362-364.

22. Manthorpe ME, Engvall E, Ruoslahti E, Longo FM, Davis GE, Varon S. Laminin promotes neuritic regeneration from cultured peripheral and central neurons. J Cell Biol 1983; 97: 1882-1890.

23. Pallini R, Fernandez E, Gangitano C, Fa AD, OlivieriSangiacomo C, Sbriccoli A. Studies on embryonic transplants to the transected spinal cord of adult rats. J Neurosurg 1989; 70: 454-462.

24. Reier PJ, Bregman BS, Wujek, JR. Intraspinal transplantation of embryonic spinal cord tissue in neonatal and adult rats. J Comp Neurol 1986; 247: 275-296.

25. Reier PJ, Houle JD. The glial scar: Its bearing on axonal elongation and transplantation approaches to CNS repair. In: Waxman SG, ed, Physiologic Basis for Functional Recovery in Neurological Disease. New York: Raven Press, 1986; 87-138. 
26. Reier PJ, Stokes BT, Thompson FJ, Anderson DK. Fetal cell grafts into resection and contusion compression injuries of the rat and cat spinal cord. Exp Neurol 1992; 115: 177-188.

27. Sandrock AW, Matthew WD. Substrate-bound nerve growth factor promotes neurite growth in peripheral nerve. Brain Res 1987; 425: 360-363.

28. Schreyer DJ, Jones EG. Growth of corticospinal axons on prosthetic substrates introduced into the spinal cord of neonatal rats. Dev Brain Res 1987; 35: 291-299.
29. Schwab ME, Caroni P. Oligodendrocytes and CNS myelin are nonpermissive substrates for neurite growth and fibroblast spreading in vitro. J Neurosci 1988; 8: 2381-2393

30. Schwab ME. Myelin-associated inhibitors of neurite growth and regeneration in the CNS. TINS 1990; 13: 452-456.

31. Siegal JD, Kliot M, Smith GM, Silver J. A comparison of the regeneration potential of dorsal root fibers into gray or white matter of the adult rat spinal cord. Exp Neurol 1990; 109: 90-97. 

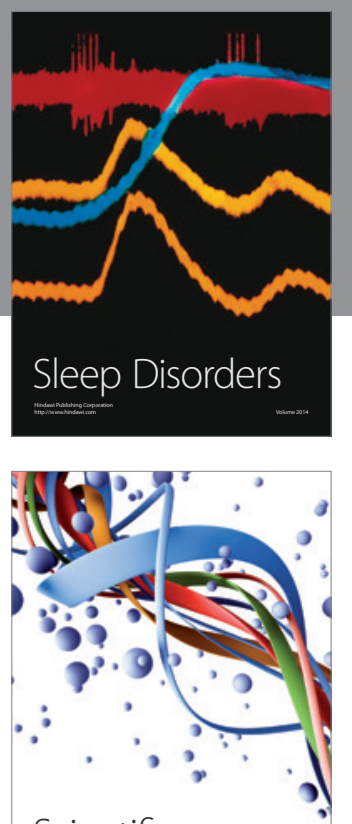

Scientifica
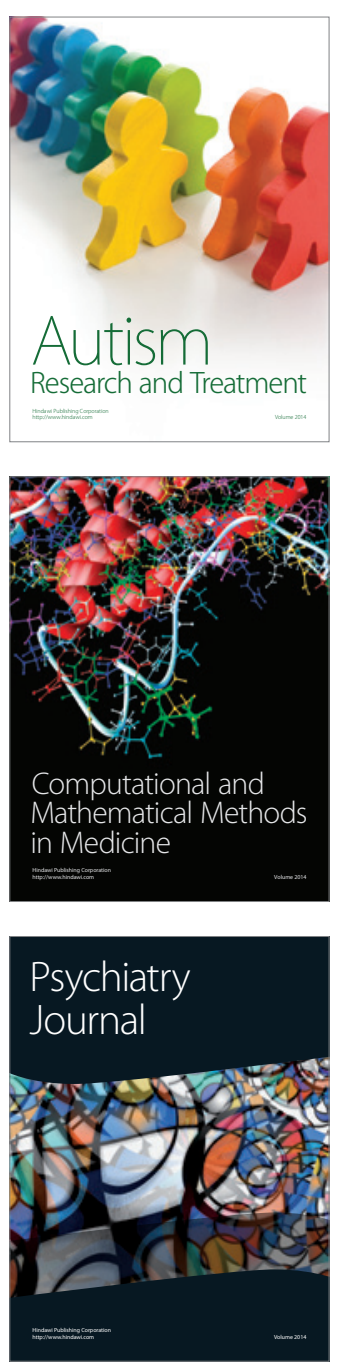
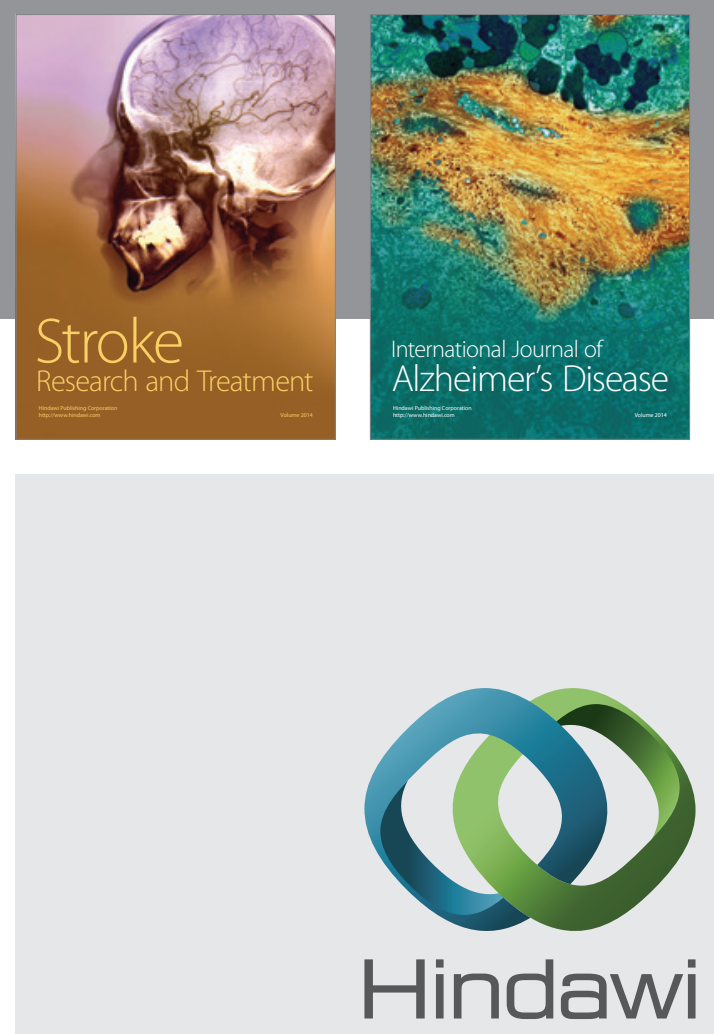

Submit your manuscripts at

http://www.hindawi.com
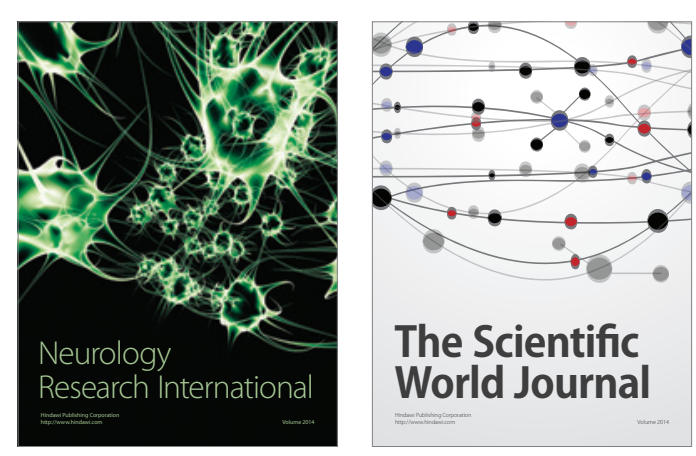

The Scientific World Journal

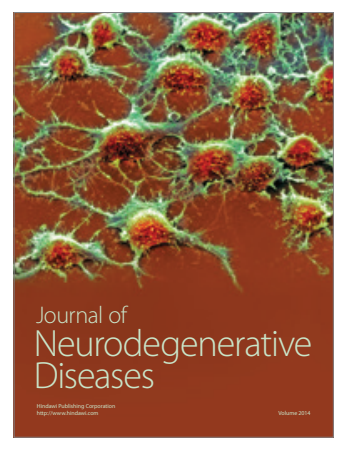

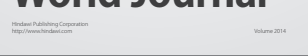

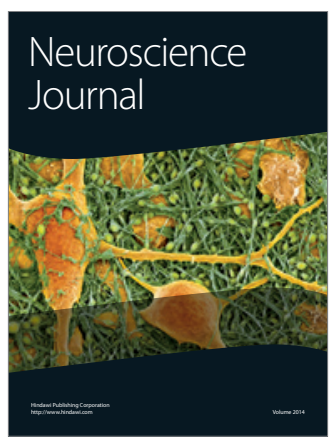

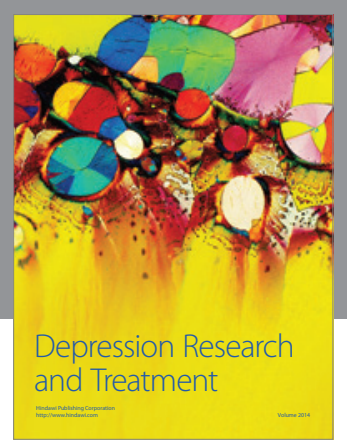
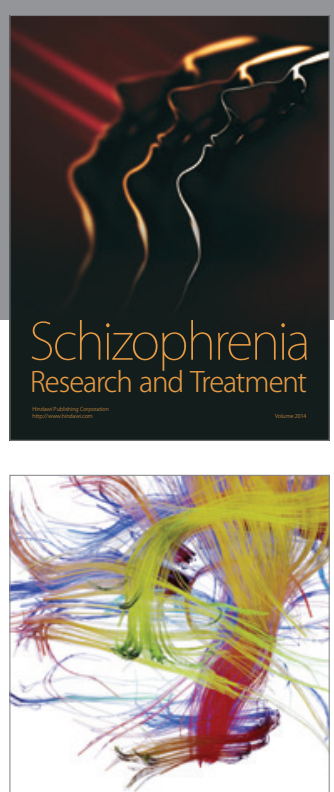

Brain Science

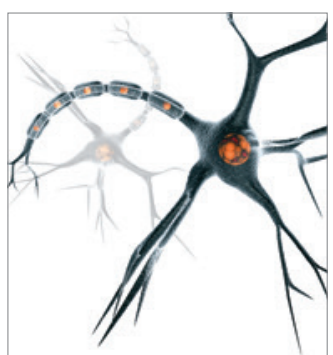

Neural Plasticity
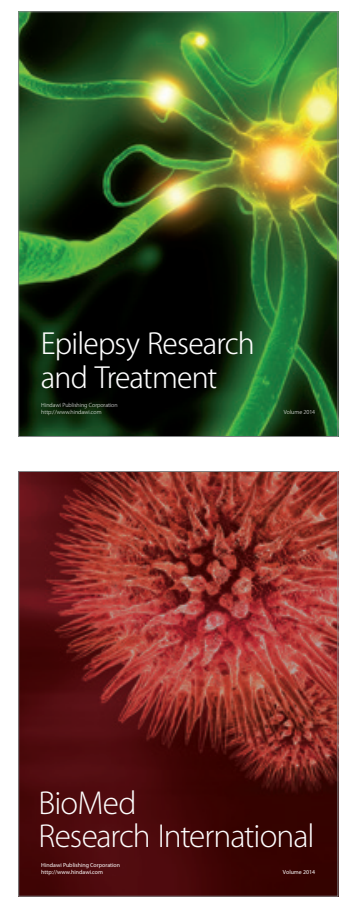

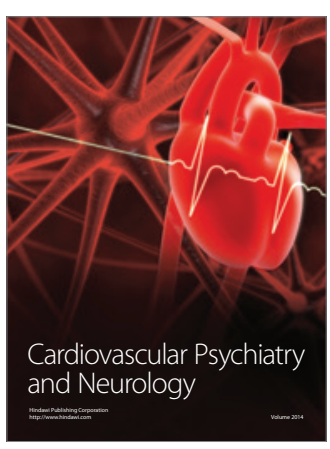

Parkinson's

Disease
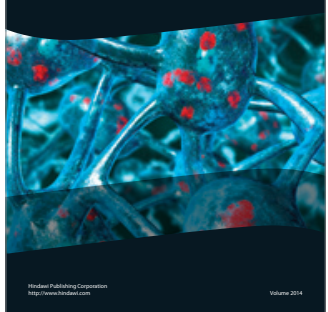